\title{
PERANAN SANDUR KEMBANG DESA DALAM PELESTARIAN KESENIAN SANDUR DI BOJONEGORO, JAWA TIMUR
}

\author{
Elvin Nuril Firdaus ${ }^{1}$, Sony Sukmawan ${ }^{2 *}$ \\ Fakultas IImu Budaya, Universitas Brawijaya, Indonesia ${ }^{12}$ \\ elvinurilf@student.ub.ac.id ${ }^{1}$, sony_sukmawan@ub.ac.id ${ }^{2 *}$
}

\begin{abstract}
Sandur is a traditional performing art that grows and develops in the area of an agrarian society. These people meet their daily needs from the production and maintenance of crops and agriculture. Sandur tells about the life of an agrarian society, the interaction between communities, farming, to the transition of an agrarian society to an urban society. One of the places where the sandur developed is Bojonegoro. Sandur once attained its heyday in Bojonegoro. Over time, sandur has been considered less relevant to modern society as there have been no adjustments to the development of the times and no regeneration. That coupled with a modernizing blow made things worse. The study aims to describe the preservation efforts of sandur through the Sandur Kembang Desa's group, a group of young men who maintain the art of sandur by informing the story to gain public acceptance. The study is done in the village of Ledok Kulon, Bojonegoro District, Bojonegoro Regency. The research used a qualitative approach by using a case study design. The data are collected through unstructured interview techniques and nonparticipant observations. The result shows that Sandur's existence is threatened with extinction because of its lack of regeneration and its stories that are considered less relevant to modern society. This has led to the decline in public interest in the arts. Sandur Kembang Desa is a group of art that encourages the Sandur in the middle of a shifting pattern of people's lives, following the modernizing current. The innovation for Sandur Kembang Desa was inspired by the lifestyle of modern society, so the show attracted people's attention. The values adopted in the Sandur Kembang Desa story are relevant in modern society, without changing the traditional values of the Sandur. It is hoped that the innovation of Sandur Kembang Desa will be able to sustain the existence of Sandur in the course of modern cultural development.
\end{abstract}

Keywords: Sandur Kembang Desa; Performing Arts; Traditional Art Innovation; Modern Society

\begin{abstract}
Abstrak
Sandur merupakan seni pertunjukan tradisional yang tumbuh dan berkembang di wilayah masyarakat agraris, yaitu masyarakat yang memenuhi kebutuhan hidupnya bersumber dari produksi dan pemeliharaan tanaman dan pertanian. Sandur mengisahkan tentang kehidupan masyarakat agraris, interaksi antarmasyarakat, bercocok tanam, hingga transisi masyarakat agraris menuju masyarakat urban. Salah satu daerah tempt berkembangnya Sandur adalah Bojonegoro. Sandur pernah mencapai masa kejayaannya di Bojonegoro. Seiring berjalannya waktu, Sandur dianggap kurang relevan dengan kehidupan masyarakat modern karena tidak ada penyesuaian dengan perkembangan zaman dan tidak ada regenerasi. Hal tersebut ditambah dengan hantaman modernisasi yang semakin memperburuk keadaan. Penelitian ini bertujuan untuk menjelaskan upaya pelestarian Sandur melalui kelompok Sandur Kembang Desa, yaitu sekelompok pemuda yang mempertahankan kesenian Sandur dengan cara menginovasi cerita dalam Sandur agar dapat diterima masyarakat. Penelitian ini dilakukan di Desa Ledok Kulon, Kecamatan Bojonegoro, Kabupaten Bojonegoro. Pendekatan yang digunakan dalam penelitian ini adalah pendekatan kualitatif dengan desain studi kasus. Data dikumpulkan melalui teknik wawancara tidak terstruktur dan observasi nonpartisipan. Hasil penelitian menunjukkan bahwa eksistensi Sandur terancam punah karena tidak adanya regenerasi dan ceritanya yang dianggap kurang relevan dengan kehidupan masyarakat modern. Hal tersebut menjadikan minat masyarakat terhadap kesenian Sandur semakin berkurang. Sandur Kembang Desa merupakan kelompok kesenian yang menginovasi Sandur di tengah pola kehidupan masyarakat yang bergeser mengikuti arus modernisasi. Inovasi Sandur Kembang Desa terinspirasi dari gaya hidup masyarakat modern, sehingga pertunjukannya mampu menarik perhatian masyarakat. Nilai-nilai yang diangkat dalam cerita Sandur Kembang Desa merupakan nilai-nilai yang relevan dengan masyarakat
\end{abstract}




\section{p-ISSN 1412-9418 e-ISSN 2502-5783 \\ Humanika Vol. 28 no 1 Copyright @2021 \\ Available online di http://ejournal.undip.ac.id/index.php/humanika}

modern, tanpa mengubah nilai-nilai tradisional Sandur. Adanya inovasi dari Sandur Kembang Desa diharapkan mampu mempertahankan eksistensi Sandur di tengah perkembangan budaya modern.

Kata kunci: Sandur Kembang Desa; Seni Pertunjukan; Inovasi Kesenian Tradisional; Masyarakat Modern

\section{Pendahuluan}

Sandur merupakan teater tradisional yang bercerita mengenai kehidupan sehari-hari masyarakat agraris, yaitu pertanian, perburuan, perdagangan, dan budaya urban. Kesenian Sandur lahir dan berkembang di beberapa wilayah Jawa Timur, seperti Bojonegoro dan Tuban. Kesenian ini umumnya berkembang di lingkungan masyarakat agraris. $\mathrm{Hal}$ tersebut seirama dengan isi cerita Sandur yang menampilkan empat tokoh utama, yaitu Balong, Petak, Tansil, dan Cawik (Rohmat, 2017). Keempat tokoh tersebut mengisahkan kehidupan masyarakat pedesaan yang condong pada bidang pertanian dan budaya urban yang dikisahkan sebagai perjalanan seorang penduduk desa yang mencari pekerjaan di kota.

Sandur berasal dari kata isan yang berarti panen dan dhur yang berarti ngedhur atau tidak akan habis dari malam hingga pagi. Kata Sandur diartikan masyarakat sebagai sandhangan dhuwur yang berarti keluhuran. Dhuwur dan luhur berkaitan dengan leluhur yang dimuliakan (Rohmat, 2017). Masyarakat Jawa menempatkan leluhur sebagai sosok yang mereka hormati dan muliakan. Sandur sebagai budaya dan tradisi yang telah lama dilaksanakan oleh masyarakat Bojonegoro dan Tuban, memiliki tujuan awal sebagai pengiring tradisi penghormatan terhadap leluhur desa. Pertunjukan Sandur pada umumnya dihadirkan dalam ritual nyekar di tempat yang terdapat dhanyang (leluhur) bersemayam.

Selain sebagai bentuk penghormatan terhadap leluhur, Sandur juga bertujuan sebagai hiburan bagi masyarakat. Perkembangan zaman menuntut kesenian Sandur adaptif terhadap pola kehidupan masyarakat modern. Masyarakat modern merupakan masyarakat yang telah mengikuti arus modernisasi sehingga mengalami pergeseran pola kehidupan. Masyarakat modern juga dapat diartikan sebagai masyarakat yang telah mengalami perubahan sosial, yaitu masyarakat yang telah mengalami pergeseran baik dari segi struktur atau tatanan di dalam masyarakat (Mulyadi, 2015). Pada dasarnya, setiap lapisan masyarakat akan mengalami perubahan sosial secara berkala, seperti perubahan pola pikir, sikap, dan kehidupan bermasyarakat. Ciri masyarakat modern menurut Neonbasu (2020:284) adalah berpikiran rasional, orientasi pada materialisme, dan individualisme. Selain itu, masyarakat modern perlu bersikap kritis dalam menyaring budaya baru dan tetap memaknai budaya tradisional. Pertunjukan Sandur merepresentasikan perubahan sosial budaya masyarakat agraris menuju budaya industri dan menggambarkan peralihan tatanan hidup masyarakat pedesaan menuju budaya kota (Rohmat, 2017).

Pada umumnya, kesenian Sandur yang berkembang di wilayah Bojonegoro memiliki kesamaan dengan Sandur di wilayah lain. Hal tersebut dikarenakan latar belakang sosial-budaya masyarakat 


\section{Available online di http://ejournal.undip.ac.id/index.php/humanika}

yang sama, sehingga menciptakan kesamaan budaya. Fokus kajian ini berada di Bojonegoro sebagai salah satu wilayah perkembangan Sandur. Masyarakat Bojonegoro merupakan masyarakat yang mulai mengalami peralihan pola kehidupan dari budaya masyarakat agraris menuju budaya industri, khususnya masyarakat yang tinggal di perkotaan. Masyarakat mulai meninggalkan kesenian tradisional ini karena dianggap tidak lagi menarik. Hal tersebut turut mempengaruhi fungsi dan kegunaan dari kesenian tersebut. Oleh sebab itu, sebagai upaya melestarikan Sandur, kelompok masyarakat pendukung kesenian tersebut yang berada di wilayah pedesaan telah melakukan inovasi. Inovasi ini dirasakan penting karena Sandur mulai kehilangan eksistensi akibat banyak masyarakat yang lebih memilih budaya modern.

Salah satu desa di Bojonegoro yang mengembangkan inovasi Sandur adalah Desa Ledok Kulon, tempat perkembangan Sandur di Ledok Kulon yang dikembangkan oleh Kelompok Sandur Kembang Desa. Sandur Kembang Desa merupakan kelompok kesenian Sandur yang didirikan atas kepedulian masyarakat terhadap kelangsungan Sandur. Sandur Kembang Desa mampu bertahan hingga saat ini di tengah arus budaya modern yang semakin pesat dan masyarakat yang lebih tertarik dengan gaya hidup modern.

Kehadiran Sandur Kembang Desa di tengah masyarakat modern tampak menguatkan nilai tradisi Sandur. Upaya penguatan pertunjukan seni pernah dikaji dalam penelitian sebelumnya oleh Anoegrajekti (2014). Melalui kajian bertajuk Janger Banyuwangi dan Menakjinggo: Revitalisasi Budaya terungkap upaya revitalisasi budaya di tengah perkembangan seni populer yang menginspirasi pegiat seni tradisi Damarwulan untuk beradaptasi dengan budaya yang tengah digemari masyarakat dengan mengubah kostum, menambah alat musik, memasukkan lagu-lagu baru yang tengah digandrungi masyarakat, menambah isi cerita, dan memadukan dengan seni lain. Sementara itu, pertunjukan Sandur di tengah peralihan budaya masyarakat agraris menuju budaya urban pernah dikaji dalam penelitian berjudul Pertunjukan Sandhur Tuban: Refleksi Peralihan Masyarakat Agraris Menuju Budaya Urban (Rohmat, 2017). Penelitian ini mengungkapkan refleksi nilai simbolik kesenian Sandur yang mampu menggugah kesadaran masyarakat di tengah perubahan ruang dan waktu, juga proses urbanisasi. Nilai tersebut dihayati dalam kehidupan dan menyatu dengan kosmis. Kesenian Sandur Tuban juga dituliskan dalam penelitian berjudul Makna Simbolik dan Nilai-Nilai Moral Kesenian Sandur di Desa Sukorejo Kecamatan Parengan Kabupaten Tuban (Mukaromah \& Puspito, 2021). Penelitian tersebut menguak makna simbolik dan nilai moral dalam Sandur, yaitu mengenai kehidupan sosial manusia terhadap sesamanya maupun Sang Pencipta. Penelitian lain dari Khusnawiyah (2019) berjudul Fungsi Kesenian Sandur Kembang Desa pada Upacara Haul Ki Andong Sari Bagi Masyarakat Ledok Kulon Bojonegoro membahas mengenai fungsi tradisi Kesenian Sandur Kembang Desa dalam upacara Haul Ki Andong Sari. Sebagian masyarakat Ledok Kulon percaya bahwa kekuatan adi kodrati yang hadir melalui pertunjukan Sandur Kembang Desa dapat memberi keberkahan dan mendatangkan rasa aman bagi masyarakat. Penelitian tersebut belum membahas mengenai upaya pelestarian Sandur di tengah peralihan kebudayaan dalam masyarakat.

Penelitian ini membahas peranan Sandur Kembang Desa dalam melestarikan budaya di tengah kehidupan masyarakat modern. Peranan yang dimaksud adalah strategi untuk mempertahankan eksistensi 


\section{p-ISSN 1412-9418 e-ISSN 2502-5783 \\ Humanika Vol. 28 no 1 Copyright @2021 \\ Available online di http://ejournal.undip.ac.id/index.php/humanika}

Sandur yang terancam punah. Padahal sasaran dari suatu kebudayaan adalah pemilik kebudayaan itu sendiri, dalam hal ini adalah masyarakat Bojonegoro. Kelahiran Sandur Kembang Desa merupakan upaya masyarakat pendukung untuk menjunjung budaya lokal tanpa mengurangi ciri khas Sandur. Lebih lanjut lagi, penelitian ini mengungkapkan berbagai inovasi seni pertunjukan yang dilakukan oleh Kelompok Sandur Kembang Desa.

\section{Metode Penelitian}

Penelitian yang bertempat di Sanggar Sandur Kembang Desa, Desa Ledok Kulon, Kecamatan Bojonegoro, Kabupaten Bojonegoro menggunakan pendekatan kualitatif. Pendekatan kualitatif bertujuan untuk mengumpulkan data lebih mendalam melalui wawancara. Kriyanto (2015:46) mengungkapkan bahwa pendekatan kualitatif berisi upaya dialektikal dan partisipatif antara peneliti dan realitas. Desain penelitian ini berwujud studi kasus. Studi kasus digunakan untuk mengkaji kasus unik dan khusus yang menarik perhatian, baik perorangan maupun kelompok (Prihatsanti, 2018). Inovasi merupakan keunikan yang dimaksudkan.

Data penelitian diperoleh dari para seniman Sandur melalui teknik wawancara tidak terstruktur dan observasi untuk menggali konteks sosial budaya (Kriyanto, 2015:52). Sementara itu, teknik wawancara dilakukan dengan pembicaraan ringan, bebas, dan bersahabat, serta disisipkan pertanyaan etnografis sebagai data yang tidak dapat direkam secara langsung. Teknik observasi nonpartisipan dilakukan dengan mengamati pertunjukan Sandur Kembang Desa. Pengamatan tidak dilakukan dengan terjun secara langsung dalam interaksi sosial, melainkan pengamatan secara virtual melalui video dan diperkuat dengan keterangan dari seniman Sandur. Dari data yang telah dikumpulkan, dilakukan analisis yang dimulai dengan pembagian tahapan pertunjukan Sandur, identifikasi ceritacerita Sandur untuk menemukan permasalahan dan mengaitkannya dengan cerita-cerita serta nilai-nilai dalam Sandur Kembang Desa.

\section{Hasil dan Pembahasan}

\section{Sandur sebagai Representasi Kehidupan Masyarakat Agraris}

Seni pertunjukan tradisional merupakan salah satu jenis kesenian yang berfungsi sebagai pengiring ritual daerah. Seni pertunjukan tradisional merupakan bagian dari masyarakat yang tidak dapat dipisahkan (Rokhim, 2018). Hal tersebut dikarenakan seni pertunjukan tradisional tumbuh dan berkembang di lingkungan masyarakat secara turun-temurun. Fungsi dan kegunaan seni pertunjukan tradisional masih tetap eksis di kalangan masyarakat tradisi, karena banyak dipertunjukkan dalam acara-acara maupun ritual penting pada suatu daerah. Salah satu masyarakat yang masih memertahankan kesenian tradisional di tengah perkembangan budaya modern adalah Desa Ledok Kulon.

Desa Ledok Kulon merupakan salah satu desa yang terletak di Kecamatan Bojonegoro yang berdekatan dengan pusat Kota Bojonegoro. Posisi geografis tersebut mempengaruhi masyarakat Ledok Kulon untuk meninggalkan pola hidup masyarakat agraris dan beralih menjadi masyarakat dengan gaya hidup modern. Masyarakat modern memiliki ciri individualis dan bersikap kritis, hal ini juga mempengaruhi gaya hidup masyarakat yang mulai meninggalkan tradisi lama. Meski begitu, Desa Ledok Kulon merupakan salah satu desa yang mampu mempertahankan kesenian Sandur. 


\section{Available online di http://ejournal.undip.ac.id/index.php/humanika}

Sandur merupakan seni pertunjukan tradisional yang tumbuh dan berkembang di tengah masyarakat agraris, yaitu masyarakat yang memenuhi kebutuhan hidupnya melalui sektor pertanian. Menurut Ratuwalu (2016) masyarakat agraris merupakan masyarakat yang sumber ekonominya bersumber pada produksi dan pemeliharaan tanaman dan tanah pertanian. Sandur lahir di beberapa daerah Jawa Timur, salah satunya Bojonegoro. Terdapat beberapa pengertian dari Sandur. Ada yang mengatakan bahwa kata Sandur adalah jalur dhosok (singkatan), yaitu berasal dari kata isan yang berarti istirahat atau sesudah bekerja dan tandhur yang berarti menanam. Dengan demikian, Sandur berarti suatu kesenian yang dipentaskan setelah tandhur atau setelah bekerja untuk membuang sengkala (marabahaya). Kesenian Sandur mengandung petuahpetuah dan ritual yang berisi tentang keselarasan antara alam dan manusia.

"Ada yang mengatakan bahwa sandur adalah jalur dhosok atau singkatan, berasal dari kata isan dan tandhur, isan dalam istilah pertanian berarti istirahat atau sesudah bekerja, sedangkan tandhur berarti menanam. Dengan demikian, sandhur bisa diartikan sebagai suatu kesenian yang dipentaskan setelah tandhur atau setelah bekerja untuk membuang marabahaya (sengkala). Kesenian sandur mengandung petuah-petuah dan terdapat beberapa ritual agar alam dan manusia itu selaras."

(MBDJ, 13 Agustus 2020)

Sandur juga bisa diartikan sebagai rasan-rasan waktu tandhur (berbincang-bincang ketika menanam atau bekerja). Hal tersebut karena dalam Sandur terdapat dialog-dialog atau tembung dalam satu adegan menanam (tandhuran). Ada pula yang mengatakan bahwa Sandur adalah sebuah sandiwara ngedhur, yaitu sandiwara atau pementasan yang dilakukan semalam suntuk untuk menghibur masyarakat. Kesenian Sandur dipertunjukkan setelah masa panen sebagai ungkapan rasa syukur para petani terhadap hasil panen yang telah didapat dan sebagai harapan agar hasil panen di musim tanam selanjutnya lebih baik lagi (Herfidiyanti, 2014). Pementasan Sandur pada umumnya dilaksanakan sekitar pukul sepuluh malam hingga menjelang waktu subuh, setelah waktu panen. Sumber lain mengatakan bahwa nama Sandur berasal dari bahasa Belanda yang artinya meneruskan permainan anak-anak pada malam hari ketika orangtua mereka sedang bekerja. Hal tersebut karena Sandur telah ada sejak zaman dahulu dan berawal dari permainan anak-anak.

"Sandur tumbuh dan berkembang di tengah masyarakat agraris atau masyarakat petani. Terdapat pemahaman yang berhubungan dengan kepercayaan mengenai teologi tanah atau hal-hal lain mengenai bercocok tanam. Dalam isi dari Sandur membuktikan bahwa Sandur berkembang di masyarakat agraris karena menceritakan caracara bercocok tanam, mengenai musim tanam, dan ceritanya berganti-ganti sesuai dengan musim tanam, tidak melulu menanam padi." (MBDJ, 13 Agustus 2020)

Sandur menceritakan tentang kehidupan manusia dan pertanian (Herfidiyanti, 2014). Masyarakat Bojonegoro juga menyebut Sandur sebagai 
Sandur menceritakan tentang kehidupan manusia dan pertanian (Herfidiyanti, 2014). Masyarakat Bojonegoro juga menyebut Sandur sebagai sanepan dunyo lan urip (perumpamaan dunia dan kehidupan), karena di dalamnya mengisahkan kehidupan manusia ketika di dunia, khususnya pada masyarakat agraris. Sanepan dunyo lan urip tersebut terbagi menjadi dua bagian, yaitu dunia besar dan dunia kecil. Dunia besar adalah seluruh kehidupan di dunia dan seisinya, dalam Sandur diwujudkan dalam bentuk blabar janur kuning (panggung), sedangkan dunia kecil merupakan tokoh dalam Sandur sendiri yang menyimbolkan 4 nasib manusia, yaitu tanah (bantala), air (bayu atau tirta), api (agni), dan udara (bowo).sanepan dunyo lan urip (perumpamaan dunia dan kehidupan), karena di dalamnya mengisahkan kehidupan manusia ketika di dunia, khususnya pada masyarakat agraris. Sanepan dunyo lan urip tersebut terbagi menjadi dua bagian, yaitu dunia besar dan dunia kecil. Dunia besar adalah seluruh kehidupan di dunia dan seisinya, dalam Sandur diwujudkan dalam bentuk blabar janur kuning (panggung), sedangkan dunia kecil merupakan tokoh dalam Sandur sendiri yang menyimbolkan 4 nasib manusia, yaitu tanah (bantala), air (bayu atau tirta), api (agni), dan udara (bowo).

"Tokoh dalam Sandur adalah Pethak itu mepet petak atau mendekati otak. Otak biasanya untuk berpikir, dalam Sandur sebagai seorang pemikir. Balong secara sanepan dari babakan bolong. Dalam tubuh manusia, terdapat lubang-lubang yang disimbolkan sebagai solusi. Ketika petak mencari pekerjaan, dia akhirnya bekerja pada Balong. Lalu ada Tangsil, kabatang kasil. Kabatang adalah ada sesuatu yang harus dijawab, sesuatu yang bila ditebak, pasti berhasil. Tangsil untuk memantik permasalahan. Lalu ada Cawik, cagak wigati, lubuk terdalam hati manusia atau bersifat mulia. Sebagai kemuliaan, sebagai keindahan dunia. Cawik di sini perempuan, sanepo yang menyimpan makna tersendiri. Germo itu blegere sukmo. Sandur kalau tidak ada Germo tidak bisa hidup."

(MBDJ, 13 Agustus 2020)

Terdapat empat tokoh dalam Sandur, yaitu Balong, Pethak, Cawik, dan Tangsil. Selain keempat tokoh tersebut, juga ada pemain lain, seperti Tukang Kandhut, Tukang Oncor, Juru Kunci, Tukang Umpet, Tukang Sajen, Germo, Panjak Hore (Herfidiyanti, 2014). Tokoh-tokoh Sandur adalah Pethak atau mepet petak (mendekati otak) yang menyimbolkan seorang pemikir, Balong atau babakan bolong (lubang dalam tubuh manusia) sebagai sosok yang memberikan solusi, Tangsil atau kabatang kasil (sesuatu yang bila ditebak, pasti berhasil) yang berperan untuk memantik permasalahan, dan Cawik atau cagak wigati (kemuliaan hati manusia) sebagai simbol kemuliaan manusia. Ada pula Germo yang memimpin pertunjukan Sandur.

Pertunjukan Sandur diawali dengan kegiatan sebelum pertunjukan, yaitu ritual setren untuk meminta berkah kepada leluhur dan pertunjukan Sandur dapat berjalan lancar. Pertunjukan Sandur terdiri atas tiga bagian, yaitu bagian pembuka, bagian cerita, dan bagian penutup. Sandur dibuka dengan tembang-tembang, berias, dan tari Jaranan. Bagian cerita diisi oleh pertunjukan drama yang diperankan oleh Pethak, Balong, Tangsil, Cawik, Germo sebagai sutradara, tarian Jaranan dengan iringan tembang para Panjak Hore. 


\section{Available online di http://ejournal.undip.ac.id/index.php/humanika}

Pertunjukan Sandur ditutup dengan atraksi kalongking.

Pertunjukan Sandur menceritakan tentang kehidupan masyarakat pertanian, hubungan antarmasyarakat, dan kehidupan masyarakat petani pada umumnya, seperti mencari pekerjaan, menggarap lahan pertanian, saling mengejek, dan kekurangan uang. Konflikkonflik yang dihadirkan dalam cerita merupakan konflik yang umum terjadi di tengah masyarakat agraris, bahkan cerita tandhur juga disesuaikan dengan musim tanam.

Teater tradisional ini masih berkembang di Desa Ledok Kulon yang sedang menghadapi ancaman kepunahan. Hal tersebut disebabkan bahwa Sandur sebagai budaya tradisional telah dianggap kuno dan tidak mengikuti perkembangan zaman, sehingga banyak ditinggalkan. Tantangan bagi seniman Sandur adalah mengolah cerita secara ringan dan baru, bukan cerita yang serius dan berat (TKM, 21 September 2020).

Salah satu tantangan yang dihadapi seniman Sandur adalah cara menyikapi pola kehidupan masyarakat modern agar mereka tidak kehilangan jati diri sebagai masyarakat yang hidup di tengah kesenian Sandur. Apabila masyarakat tidak mampu menyaring budaya yang masuk, maka eksistensi Sandur di tengah masyarakat modern akan meredup. Meskipun demikian, masih ada golongan masyarakat yang mempertahankan kebudayaan setempat, seperti para orang tua atau sesepuh. Pada sudut pandang tertentu, masyarakat tidak bisa menolak adanya modernisasi, sedangkan perubahan dan perkembangan selalu menghargai budaya yang khas dari setiap bangsa (Neonbasu, 2020:281), sehingga cara menyikapi pola kehidupan baru dalam masyarakat adalah dengan turut mengikuti arus perkembangan zaman saat ini. Hal tersebut dilakukan agar eksistensi Sandur, sebagai kesenian masyarakat Bojonegoro yang telah ada sejak zaman dahulu tidak meredup.

\section{Peranan Sandur Kembang Desa Dalam Inovasi Sandur}

Kesenian tradisional merupakan salah satu jenis budaya tradisional yang digunakan untuk mengekspresikan estetika dalam jiwa manusia (Andri, 2016). Kesenian tradisional pada umumnya berfungsi sebagai pengiring ritual. Selain itu, kesenian tradisional juga berfungsi sebagai media pendidikan, hiburan, dan penggambaran peristiwa tertentu.

Seni pertunjukan tradisional merupakan salah satu bentuk kesenian tradisional. Seni pertunjukan tradisional banyak difungsikan untuk pengiring acara ritual, khususnya masyarakat agraris sebagai wujud syukur atas melimpahnya panen mereka dan berharap agar panen selanjutnya mendapatkan hasil yang lebih baik. Seni pertunjukan tradisional di dalam pelaksanaannya melibatkan tiga hal, pelaku seni, penikmat seni, dan penguasa (Anoegrajekti, 2014). Pelaku seni adalah orang-orang yang mengkreasikan seni dan mempertunjukkannya kepada masyarat. Penikmat seni adalah masyarakat tersebut atau orang yang menikmati hasil karya pelaku seni, sedangkan penguasa adalah pihak-pihak yang mengontrol, menata, dan mengawasi hasil kreasi-kreasi seni tersebut. Seni pertunjukan dilakukan dengan mengikuti tuntutan pasar. Hal tersebut dilakukan agar penonton tertarik dengan seni pertunjukan tersebut.

Fungsi dari kesenian tradisional seiring perkembangan zaman mengalami pergeseran. Modernisasi membawa dampak bagi perkembangan budaya, salah satunya adalah Sandur. Eksistensi Sandur Bojonegoro mulai meredup karena masyarakat lebih memilih budaya-budaya modern yang lebih atraktif, sedangkan Sandur dianggap kuno karena ceritanya 
sudah tidak sesuai dengan masyarakat sekarang. Fungsi awal Sandur yang semula bersifat sakral bergeser menjadi kegiatan hiburan.

"Meredupnya Sandur di kalangan masyarakat menggerakkan hati pemuda-pemuda Ledok untuk menginovasi Sandur."

(OK, 7 Desember 2020)

Rogers mengungkapkan bahwa inovasi merupakan suatu ide, gagasan, objek, dan praktik yang dilandasi dan diterima sebagai hal baru oleh individu maupun kelompok untuk diaplikasikan atau diadopsi (Rokhim, 2018). Inovasi dilakukan untuk memperbarui suatu hal agar dapat diterima oleh masyarakat dan tidak dianggap ketinggalan zaman. Apabila dikaitkan dengan kesenian tradisional, inovasi berfungsi untuk memperbarui suatu kesenian agar tidak tenggelam di antara kesenian-kesenian modern yang lebih digemari masyarakat.

Pemuda Desa Ledok Kulon membentuk Sandur Kembang Desa berawal dari perkumpulan pemudapemuda yang bergelut di bidang kesenian dalam suatu kelompok bernama Sanggar Sayap Jendela. Kelompok tersebut akhirnya membentuk Sandur Kembang Desa dengan menampilkan Sandur yang telah dimodifikasi. Sandur Kembang Desa bertujuan untuk melestarikan Sandur agar eksistensinya tetap bertahan di tengah masyarakat modern. Pelestarian budaya merupakan suatu upaya menjaga dan melestarikan warisan budaya agar mampu berkesinambungan dengan lajunya modernisasi dan globalisasi (Rachman, 2012). Pelestarian budaya pada Sandur dilakukan agar Sandur tetap eksis di tengah masyarakat modern.

Salah satu strategi pelestarian seni tradisi adalah inovasi. Inovasi berkaitan erat dengan kreativitas, yaitu suatu kemampuan untuk mengombinasi dan mengolah berdasarkan unsur-unsur yang telah ada sebelumnya (Tjaturrini, 2018). Inovasi dalam seni pertunjukan tradisional dapat dilihat melalui unsur-unsurnya, yaitu elemen dasar dan elemen artistik (Kurniawan, 2010: 18). Elemen dasar pada Sandur yaitu naskah cerita, sutradara, pemain, dan penonton, sedangkan elemen artistik yaitu tata panggung, tata rias, tata busana, tata cahaya, tata suara, properti, musik pengiring, dan olah tubuh, sukma, dan suara. Terdapat beberapa perkembangan pada setiap elemen, seperti naskah cerita yang mulai disesuaikan dengan kehidupan masyarakat modern, peran pemain Sandur mulai terbagi secara merata, dan terdapat beberapa variasi musik pengiring yang lebih fleksibel dalam setiap pertunjukan. Meskipun begitu, susunan pertunjukan Sandur tidak mengalami perubahan. Hal tersebut dilakukan untuk menghormati para seniman Sandur terdahulu yang telah menyusun pertunjukan dengan apik.

Masyarakat Ledok Kulon yang semula sebagian besar adalah masyarakat agraris mulai beranjak menjadi masyarakat modern, sehingga cerita-cerita Sandur yang banyak mengusung konsep pertanian dianggap tidak relevan. Sandur Kembang Desa menyuguhkan jawaban atas kegelisahan masyarakat terhadap Sandur dengan menghadirkan cerita-cerita yang sesuai dengan kehidupan saat ini dan mengikuti tuntutan pasar tanpa menghilangkan esensi Sandur. Topik-topik yang diusung merupakan bentuk kritik sosial yang disajikan bersama lelucon, sedangkan Sandur sendiri lebih berfokus pada permasalahan masyarakat agraris menuju masyarakat urban (Rohmat, 2017). Penyajian baru dari Sandur diupayakan agar Sandur dapat diterima kembali oleh masyarakat. Melalui penyajian baru ini, respons masyarakat terhadap Sandur 
Kembang Desa terkesan positif dan pesanpesan pun dapat tersampaikan dengan baik (OK, wawancara7 Desember 2020).

Sandur Kembang Desa pada umumnya dipentaskan di lapangan luas. Cerita-cerita yang dibawakan oleh pegiat Sandur Kembang Desa selalu mendapat respons positif dari masyarakat dan pesan moral yang diselipkan melalui cerita dapat tersampaikan dengan efektif. Hal tersebut dikarenakan cerita yang disajikan relevan dengan permasalahan masyarakat saat ini, diselingi lelucon, dan durasi waktu yang singkat, sehingga masyarakat sebagai penonton tidak merasa bosan. Selain itu, Sandur Kembang Desa memiliki fungsi khusus dalam upacara Haul Ki Andong Sari (Khusnawiyah, 2019). Sebagian masyarakat Ledok Kulon memiliki kepercayaan terhadap kekuatan adi kodrati yang hadir dari luar diri manusia. Adanya pertunjukan Sandur Kembang Desa dalam upacara tersebut diharapkan mampu memberikan berkah serta rasa aman kepada masyarakat.

Sandur Kembang Desa menjadi salah satu upaya pelestarian budaya Bojonegoro di tengah pergeseran pola hidup masyarakat menuju budaya modern. Sandur Kembang Desa diupayakan dapat mengembalikan serta mengenalkan kepada masyarakat tentang budaya setempat agar masyarakat tidak kehilangan jati dirinya.

\section{Inovasi pada Elemen Dasar}

Elemen dasar merupakan unsur pokok dalam suatu seni pertunjukan tradisional (Kurniawan, 2010: 18). Terdapat beberapa elemen dasar, yaitu naskah, sutradara, pemain, dan penonton. Naskah cerita Sandur dikerjakan oleh Germo selaku sutradara. Naskah pada seni pertunjukan berfungsi sebagai sumber utama dalam suatu pertunjukan (Kurniawan, 2010: 18). Pada pertunjukan Sandur dulu, cerita berpusat pada aktivitas pertanian. Hal tersebut yang membuat Sandur terkesan monoton, karena tidak ada perubahan cerita. Sandur Kembang Desa menyuguhkan cerita yang lebih variatif, seperti isu-isu sosial yang ada di tengah masyarakat modern. Hal tersebut diupayakan sebagai bukti bahwa Sandur telah mengalami perkembangan.

"Pementasan Sandur diawali dengan ritual setren yang dilakukan agar pementasan berjalan dengan lancar." (MBDJ, 13 Agustus 2020)

Struktur asli Sandur diawali dengan kegiatan praacara yaitu ritual setren agar pertunjukan yang dilaksanakan dapat berjalan dengan lancar. Tahap awal pertunjukan ditandai oleh pembacaan doa-doa dan mantra yang dilakukan oleh Germo dengan mengelilingi Blabar Janur Kuning (panggung), kemudian dilanjut dengan tari Jaranan. Pertunjukan memasuki tahap inti, ketika keempat pemain utama Sandur mulai bermain peran. Sandur berdurasi cukup lama karena sebelum Germo memberikan instruksi untuk rias, pemain dilarang merias diri terlebih dahulu. Tahap akhir dari Sandur adalah Kalongking atau atraksi yang dilakukan oleh Panjak Kalongking.

Sandur Kembang Desa menginovasi beberapa struktur Sandur agar kesenian Sandur dapat diterima kembali oleh masyarakat modern. Struktur Sandur Kembang Desa tidak lagi menggunakan kegiatan praacara. Hal tersebut dilakukan karena fungsi Sandur telah bergeser menjadi fungsi hiburan dan komersial (Herfidiyanti, 2014). Tahapan awal Sandur Kembang Desa adalah kreasi Tari Jaranan Tari Jaranan pada Sandur Kembang Desa tidak lagi terdapat unsur magis, tetapi merupakan kreasi tari berdasarkan hasil latihan dengan gerakan-gerakan dan formasi sederhana. Berbeda dengan Sandur dulu, tari Jaranan dilakukan oleh 
orang awam yang melakukan gerak tari setelah kesurupan.

"Perbedaan Sandur dulu dan Sandur Kembang Desa terletak pada peran tokoh Cawik dan cerita. Pada Sandur dulu, tokoh Cawik tidak memiliki dialog, perannya hanya menari pada adegan-adegan tertentu, sedangkan pada kelompok Sandur sekarang, Cawik memiliki porsi akting atau masuk peran."

(OK, 19 Desember 2020)

Pada tahap inti, inovasi Sandur Kembang Desa terletak pada cerita yang dibawakan dan peran tokoh Cawik sebagai pemain Sandur. Cerita yang diusung Sandur Kembang Desa lebih variatif, mengenai problematika masyarakat modern yang lebih kompleks. Selain itu, tokoh Cawik bukan hanya menari, tetapi juga berdialog. Pada tahap akhir, Kalongking ditampilkan dengan atraksi sederhana. Pada Sandur Kembang Desa, tari Jaranan dan Kalongking tidak selalu ditampilkan, tetapi mengikuti permintaan penyelenggara acara. Dengan demikian, kelengkapan tahapan pertunjukan Sandur menyesuaikan kebutuhan acara.

\section{Inovasi Pada Elemen Artistik}

Elemen artistik merupakan unsur pendukung dalam suatu pertunjukan (Kurniawan, 2010: 22). Elemen artistik pada seni pertunjukan adalah tata panggung, tata rias, tata busana, tata cahaya, properti, musik pengiring, dan olah tubuh. Bagi kesenian Sandur, elemen artistik memiliki makna secara simbolik, sehingga kehadirannya dianggap penting (Mukaromah \& Puspito, 2021). Secara keseluruhan, tidak terdapat perubahan pada elemen artistik di dalam pertunjukan Sandur Kembang Desa, tetapi terdapat perkembangan dalam pemilihan musik pengiring.

\begin{abstract}
"Alat musik dulu, gendang dan gong, dan diiringi nyanyian. Kalau sekarang, saron, demung, gendang, gender, gong, dan siter. Pemilihan alat musik tergantung kreativitas penggarap. Properti yang digunakan adalah bambu untuk obor, janur, selendang, kain kerudung, ubo rampe berisi ketupat dan lepet, dan 4 kursi anak wayang. Ketupat dan lepet digantung pada blabar dan diakhir acara akan dibagikan kepada penonton agar mendapat barokahnya."

(OK, 19 Desember 2020)
\end{abstract}

Pada Sandur Kembang Desa, terdapat beberapa variasi musik pengiring. Apabila sebelumnya alat musik pada Sandur adalah Kendang dan Gong Bumbung (Herfidiyanti, 2014), pertunjukan Sandur Kembang Desa terdapat alat musik tambahan, yaitu saron, demung, gender, dan setir. Alat musik yang digunakan tidak pakem, tetapi menyesuaikan kreativitas dari sutradara. Selain itu, pada setiap tahapan pertunjukan terdapat iringan tembang yang dinyanyikan oleh Panjak Hore. Tembang-tembang yang dinyanyikan sama dengan tembang-tembang Sandur dahulu, seperti Aja Haru Biru, Mendhung Sepayung, Tulak Kala, Sorak Hore, dan beberapa tembang lainnya.

Properti yang digunakan dalam pertunjukan Sandur Kembang Desa adalah bambu untuk obor, janur, kain kerudung, selendang, ubo rampe berisi ketupat dan lepet, dan 4 kursi anak wayang. Bambu tersebut berbentuk panjang seukuran obor. Pada awal pertunjukan, obor dibawa Germo sambil mengelilingi blabar dan Panjak Hore menyanyikan beberapa tembang sebagai tanda bahwa pertunjukan Sandur telah dimulai. Properti lain yang digunakan adalah janur yang merupakan properti utama pada blabar. 


\section{Available online di http://ejournal.undip.ac.id/index.php/humanika}

Janur ditali di sekeliling blabar, sehingga panggungnya disebut Blabar Janur Kuning. Pada janur tersebut digantung ubo rampe, yaitu ketupat dan lepet untuk dibagikan kepada penonton di akhir acara agar mendapatkan berkah.

Properti berikutnya adalah selendang yang digunakan oleh penari dan empat (4) kursi untuk digunakan oleh pemain Sandur. Fungsi kain kerudung adalah sebagai penutup kepala pemain ketika pertama kali masuk blabar, sedangkan selendang digunakan oleh penari. Properti-properti yang digunakan tersebut tidak terdapat perubahan untuk menghormati para pendahulu yang telah memilih berbagai properti yang memiliki berbagai nilai filosofis.

Pertunjukan Sandur Kembang Desa berdurasi kurang lebih satu jam. Durasi yang pendek berfungsi untuk menghindari kejenuhan pada penonton dan pesan yang disajikan dapat tersampaikan dengan pertunjukan yang singkat. Meskipun begitu, Sandur Kembang Desa berusaha mempertahankan akar dari Sandur agar esensi dari kesenian tradisi ini tidak hilang.

\section{Simpulan}

Sandur merupakan kesenian teater tradisional yang tumbuh dan berkembang di wilayah masyarakat agraris, seperti Bojonegoro dan Tuban. Sandur umumnya bersifat sakral, berfungsi sebagai pengiring acara, pengobatan, maupun sebagai hiburan. Cerita-cerita yang diangkat dalam Sandur mengenai kehidupan masyarakat agraris yang bermatapencaharian sebagai petani, masyarakat yang mencari pekerjaan, dan perubahan masyarakat agraris menuju masyarakat urban. Namun, eksistensi Sandur semakin redup seiring dengan adanya modernisasi di tengah masyarakat. Masyarakat lebih memilih budaya-budaya yang dianggap lebih atraktif. Hal tersebut menggerakkan hati pemuda Desa Ledok Kulon, Kecamatan Bojonegoro, untuk membentuk kelompok Sandur Kembang Desa. Sandur Kembang Desa merupakan inovator Sandur masa kini. Tema cerita yang dibawakan menyesuaikan dengan permasalahan masyarakat modern. Elemen dasar dan elemen artistik pertunjukan tradisional ini juga mengalami penyesuaian dan modifikasi. Dengan cara ini, Sandur Kembang Desa mampu membangkitkan eksistensi Sandur di tengah pola kehidupan masyarakat modern yang sangat dinamis.

\section{Referensi}

Andri, L. (2016). Seni Pertunjukan Tradisional di Persimpangan Zaman: Studi Kasus Kesenian Menak Koncer Sumowono Semarang. Humanika, 23(2), 25-31. doi:https://doi.org/10.14710/humani ka.v23i2.13642

Anoegrajekti, N. (2014). Janger Banyuwangi dan Menakjinggo: Revitalisasi Budaya. LITERASI, 4(1), 116-127.

Herfidiyanti, N. M. (2014). Seni Sandur Ronggo Budoyo Tahun 1990-2014. AVATARA: e-Journal Pendidikan Sejarah, 2(3), 155-168.

Khusnawiyah, W. (2019). Fungsi Kesenian Sandur Kembang Desa pada Upacara Haul Ki Andong Sari Bagi Masyarakat Ledok Kulon Bojonegoro. Doctoral dissertation, INSTITUS SENI INDONESIA (ISI) SURAKARTA.

Kriyanto, R. (2015). Public Relations, Issue \& Crisis Management: Pendekatan Critical Public Relation, Etnografi kritis, \& Kualitatif (Kedua ed.). Jakarta: Penerbit Kencana. 
Kurniawan, A. \&. (2010). Menggelar

Pertunjukan Seni Teater. Jakarta:

Multi Kreasi Satudelapan.

Mukaromah, R., \& Puspito, P. (2021). Makna

Simbolik dan Nilai-nilai Moral

Kesenian Sandur di Desa Sukorejo

Kecamatan Parengan Kabupaten

Tuban. APRON: Jurnal Pemikiran Seni

Pertunjukan, 2(16).

Mulyadi, M. (2015). Perubahan Sosial

Masyarakat Agraris ke Masyarakat Industri dalam Pembangunan

Masyarakat di Kecamatan Tamalate

Kota Makassar. Jurnal Bina Praja, 7(4),

311-322.

doi:https://doi.org/10.21787/jbp.07.2

015.311-321

Neonbasu, G. (2020). Sketsa Dasar: Mengenal Manusia dan Masyarakat (Pintu

Masuk IImu Antropologi). Jakarta:

Penerbit Buku Kompas.

Prihatsanti, U. d. (2018). Menggunakan Studi Kasus sebagai Metode Ilmiah dalam Psikologi. Buletin Psikologi, 26(2), 126136.

doi:10.22146/buletinpsikologi.38895

Rachman, M. (2012). Konservasi Nilai dan Warisan Budaya. IJC: Indonesian Journal of Conservation, 1(1), 30-39.
Ratuwalu, B. (2016). Transisi Masyarakat Agraris Menuju Masyarakat Industrial Indonesia. Journal of Industrial Engineering, 1(2). doi:http://dx.doi.org/10.33021/jie.v1i 2.343

Rohmat, \&. D. (2017). Pertunjukan Sandhur Tuban: Refleksi Peralihan Masyarakat Agraris Menuju Budaya Urban. Panggung, 27(1), 74-86. doi:http://dx.doi.org/10.26742/pangg ung.v27i1.236

Rokhim, N. (2018). Inovasi Kesenian Rakyat Kuda Lumping di Desa Gandu, Kecamatan Tembarak, Kabupaten Temanggung. Greget: Jurnal Pengetahuan dan Penciptaan Tari, 17(1), 83-90. doi:https://doi.org/10.33153/grt.v17i 1.2299

Suryo, D. (2009). Transformasi Masyarakat Indonesia dalam Historiografi Indonesia Modern. Yogyakarta: STPN Press.

Tjaturrini, D. (2018). Celengsai: Kreativitas dan Inovasi Pekerja Seni dalam Mempertahankan Kesenian Tradisional. Jurnal IImiah Lingua Idea, 9(2). Retrieved Desember 16, 2020, from http://jos.unsoed.ac.id/index.php/jli/ article/view/1171 